MODELING, IDENTIFICATION AND CONTROL, 2003, VOL. 24, No. 2, 99-113

doi:10.4173/mic.2003.23

\title{
Dynamic Optimization and Production Planning of Thermal Cracking Operation
}

\author{
EMIL H. EDWIN* and JENS G. BALCHEN†
}

Keywords: Steam cracker, coke, dynamic simulation, modelling, economics, radiation

\begin{abstract}
This work addresses the dynamic optimization of the production period of thermal crackers with respect to coke formation in the cracking coil and transfer line exchanger. Optimal time dependent trajectories of feed rate, steam to hydrocarbon ratio, and reaction severity are calculated. The net earnings based on the price of hydrocarbons, fuel, steam, decoking, and maintenance cost are maximized. All important operational constraints are included and the optimization problem is solved using parameterized free variable trajectories (piece wise constant) and a standard SQP package. Rigorous distributed physical models are used and calculation show that dynamic optimization gives up to $2 \%$ higher net earnings (earnings - expenses) than conventional steady state optimization performed on the same models. This is in the same range as earnings reported from steady state optimization implementations alone.
\end{abstract}

\section{Introduction}

There are several processes which may be used in ethylene production, but the process favored in modern practice is the cracking reactions, also called steam cracking or pyrolysis. Hydrocarbon feed stock mixed with process steam are introduced into tubular reactors (cracking coils) with short residence time and high temperatures. The process steam is basically an inert gas and it serves the purpose to increase olefin selectivity and to reduce coke formation by reducing the hydrocarbon partial pressure. The paraffinic feed stock is thermally cracked into mainly olefins, aromates, methane and hydrogen. The homogenous cracking reactions are endothermic and need energy input in order to reach gas temperatures as high as $800-900^{\circ} \mathrm{C}$ at the coil outlet. Thus, several cracking coils are placed vertically inside a fire box and heated with hydrogen/methane fueled burners (Figure 2). The reactions are quenched in the transfer line exchanger (TLX) and steam is generated. Steam is superheated and feed stock and process steam are preheated with the flue gas in the convection section of the furnace.

During a production period coke is formed on the inner tube surface of the cracking coils and the TLX. The coke formation reduces the olefin selectivity mainly because of the increased pressure drop in the cracking coil. The coke formation also usually leads to excitation of one or more of the furnace operational constraints at the end of the production period. Coke is burned of with steam and air during a 1-4 days decoking period. The decoking operation has to be done every 10-80 days depending on furnace design and operating philosophy.

\footnotetext{
*Corresponding author, Statoil R\&D, 7005 Trondheim, Norway, Tel: 47735847 04, Fax: 47735847 92, E-mail: emed@statoil.no

$\dagger$ NTNU, Teknisk Kybernetikk 7491 Trondheim, Norway.

Reprinted from Chemical Engineering Science 56 (2001), pp. 989-997, copyright 2001, with permission from Elsevier Science.
} 
Several crackers in a plant are operated in a production sequence with one of the cracker off stream for decoking and maintenance most of the time. The production/ decoking sequence, the time-dependent excitation of furnace constraints and the nonlinearity of the process indicate that the process parameters and the production schedule could be optimized with time as one dimension. The present work is concerned with the calculation of optimal production time period and optimal time dependent trajectories of the most important process parameters.

\section{Models}

The mass, momentum and energy balances of the convection section, tubular reactor, the TLX with steam drum and the firebox are closely interlinked. Selected components of the model are described below. A complete presentation of all the mathematical models with iteration algorithms is given in Edwin (1994).

\subsection{Pyrolysis reactions}

It is generally accepted that thermal cracking of hydrocarbons proceeds through chain radical reactions (Willems et. al. 1988, Dente et al. 1990) and chain radical reaction schemes has been publiched previously (Sundaram, 1978 and Dente et al. 1983). The main elementary reactions may be divided into seven different groups (Dente, 1983):

1. Chain-initiation reactions-Unimolecular:

$$
\mathrm{R}-\mathrm{R}^{\prime} \rightarrow \mathrm{R} \cdot+\mathrm{R}^{\prime} \cdot\left(\text { example: } \mathrm{C}_{2} \mathrm{H}_{6} \rightarrow 2 \mathrm{CH}_{3} \cdot\right)
$$

and bimolecular $\mathrm{R}^{\prime} \mathrm{H}$ in an unsaturated hydrocarbon:

$$
\mathrm{RII}+\mathrm{R}^{\prime} \mathrm{II} \rightarrow \mathrm{R} \cdot+\mathrm{R}^{\prime} \mathrm{II} \cdot\left(\text { example: } \mathrm{C}_{2} \mathrm{II}_{6}+\mathrm{C}_{2} \mathrm{II}_{4} \rightarrow 2 \mathrm{C}_{2} \mathrm{HI}_{5}\right. \text { ) }
$$

2. Hydrogen-abstraction reactions:

$$
\mathrm{R} \cdot+\mathrm{R}^{\prime} \mathrm{H} \rightarrow \mathrm{RH}+\mathrm{R}^{\prime} \cdot\left(\text { example: } \mathrm{CH}_{3} \cdot+\mathrm{C}_{2} \mathrm{H}_{6} \rightarrow \mathrm{CH}_{4}+\mathrm{C}_{2} \mathrm{H}_{5} \cdot\right)
$$

3. Radical-decompostion reactions:

$$
\mathrm{R} \cdot \rightarrow \mathrm{RH}+\mathrm{R}^{\prime} \cdot\left(\text { example: } 1-\mathrm{C}_{3} \mathrm{H}_{7} \cdot \rightarrow \mathrm{C}_{2} \mathrm{H}_{4}+\mathrm{CH}_{3} \cdot\right)
$$

4. Radical-addition reactions to unsaturated molecules:

$$
\mathrm{R} \cdot+\mathrm{R}^{\prime} \mathrm{H} \rightarrow \mathrm{R}^{\prime \prime} \text { (example: } \mathrm{CH}_{3} \cdot+\mathrm{C}_{2} \mathrm{H}_{4} \rightarrow 1-\mathrm{C}_{2} \mathrm{H}_{7} \cdot \text { ) }
$$

5. Chain termination reactions by radical recombination:

$$
\mathrm{R} \cdot+\mathrm{R}^{\prime} \cdot \rightarrow \mathrm{R}-\mathrm{R}^{\prime}\left(\text { example: } \mathrm{C}_{2} \mathrm{H}_{3} \cdot+\mathrm{C}_{2} \mathrm{H}_{5} \cdot \rightarrow 2 \mathrm{C}_{2} \mathrm{H}_{4}\right. \text { ) }
$$

and by disproportionation of radicals:

$$
\mathrm{R} \cdot+\mathrm{R}^{\prime} \cdot \mathrm{RH}+\mathrm{R}^{\prime \prime} \mathrm{H}\left(\text { example: } \mathrm{C}_{2} \mathrm{H}_{3} \cdot+\mathrm{C}_{2} \mathrm{H}_{5} \cdot \rightarrow 2 \mathrm{C}_{2} \mathrm{H}_{4}\right. \text { ) }
$$

6.Purely molecular reactions:

$$
\mathrm{RH}+\mathrm{R}^{\prime} \mathrm{H} \rightarrow \mathrm{R}^{\prime \prime} \mathrm{H}+\mathrm{R}^{\prime \prime \prime} \mathrm{H} \text { (example: } \mathrm{C}_{2} \mathrm{H}_{6} \rightarrow \mathrm{C}_{2} \mathrm{H}_{4}+\mathrm{H}_{2} \text { ) }
$$

7. Radical-isomerization reactions:

$$
\mathrm{R}^{\prime} \cdot+\mathrm{R}^{\prime \prime} \cdot\left(\text { example: } 1-\mathrm{C}_{3} \mathrm{H}_{7} \cdot \rightarrow 2 \mathrm{C}_{3} \mathrm{H}_{7} \cdot\right)
$$




\section{Dynamic Optimization and Production Planning of Thermal Cracking Operation 101}

The resulting reaction scheme used for ethane, propane, $i$-butane, and $n$-butane feed stocks contains 680 reactions comprising 17 propagating radicals and 37 molecular species. The work presented by Dente et. al. (1983) serves as a basis for this pyrolysis model. However, the kinetic scheme published by Dente et. al. (1983) was presented in a reduced form and it was found to be too concise. Some kinetic extensions had to be made in Edwin (1994) and the parameters was tuned and verified with large amounts of laboratory and industrial data. Some of the data are shown in Table 2 and Figure 1. The number of independent parameters are reduced by reaction group contribution rules and by defining reference reactions within a reaction class, and correct for symmetrical variations and molecular bond positions in specific reactions. (Dente et. al. 1983, Willems et al. 1988a, b, Edwin 1994).
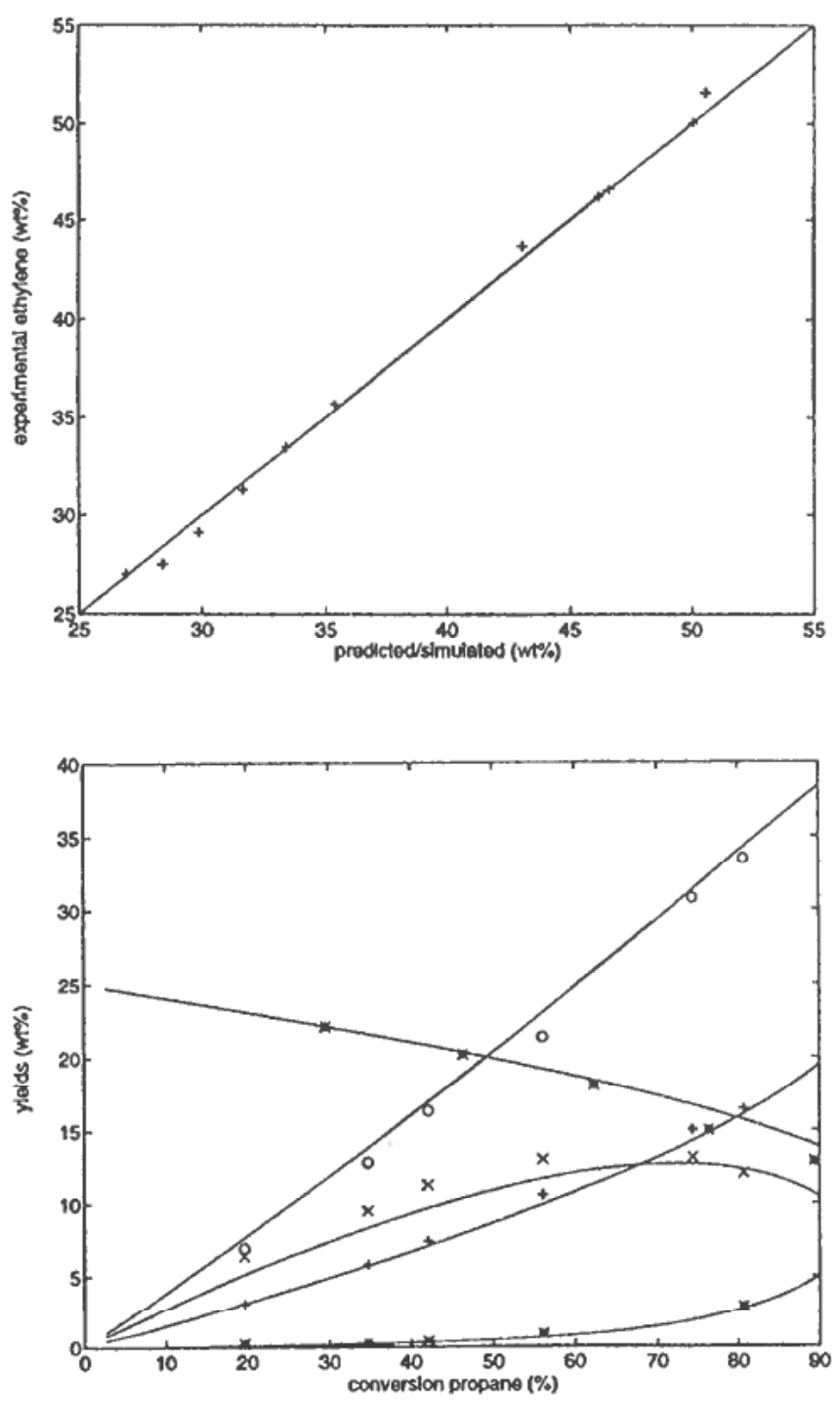

Figure 1. (a) Predicted and measured ethylene composition (11 industrial data sets), (b) Predicted methane + , ethylene $\mathrm{O}$ ethane, propylene $\times$ and $\mathrm{C}_{5}+$ composition $*(25 / 75$ ethane/propane feed, Froment (1976) 


\subsection{Tubular reactor}

The high Reynolds number $\left(R e_{D}=10^{5}-10^{6}\right)$ in the tubular reactor coils enable ideal plug flow assumptions. Thus, material, momentum and energy balances gives:

$$
\begin{gathered}
\frac{\mathrm{d} w_{j}}{\mathrm{~d} z}=\frac{M_{j}}{G} \sum_{i} r_{i} S(i, j) \\
\frac{\mathrm{d} \rho}{\mathrm{d} z}=\left(\frac{G}{\rho}\right)^{2}\left[\frac{\mathrm{d} \rho}{\mathrm{d} z}-2 f(\rho / D)\right] \\
G C_{p m} \frac{\mathrm{d} T}{\mathrm{~d} z}=\sum_{i} r_{i} \Delta H_{i}+\frac{2}{\pi D} \int^{2 \pi} U(\phi)\left(T_{w}(\phi)-T\right) \mathrm{d} \phi
\end{gathered}
$$

The energy input from the firebox is simplified in equation (3). The overall heat transfer $(U)$ includes convective heat transfer from the inner surface of the growing coke layer to the flowing gas and it also includes heat conduction in the tube material and coke layer. Circumferential heat fluxes in the tube and coke layer are ignored in the calculations because they are small compared to the total heatfluxes (50-150 $\left.\mathrm{kW} / \mathrm{m}^{2}\right)$. The overall heat transfer coefficient $(U)$ is dependent of the cylindrical coordinate $\phi$ ( $z$ coordinate defined by flow direction) because the circumferential tube wall temperature $\left(T_{w}(\phi)\right)$ and thus the coking rates are greatly dependent on the tube configuration and the orientation towards the burners. Simulations indicate that differences between maximum and minimum circumferential tubeskin temperature in stagged tube configuration is as high as $60^{\circ} \mathrm{C}$ (Figure 2). This indicates how

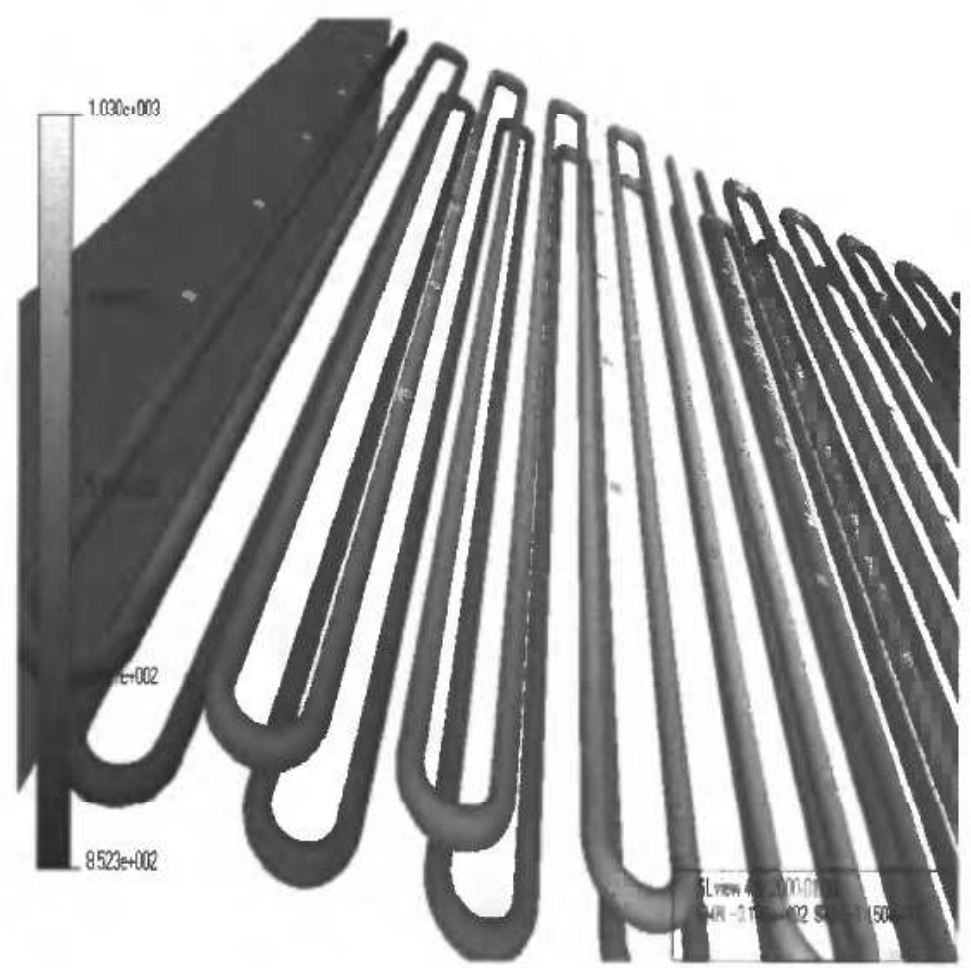

Figure 2. Simulated tubeskin temperature $\left({ }^{\circ} \mathrm{C}\right)$, visualized with GLview 3D. 
important it is to calculate temperatures and coking rates circumferential to the tubes in order to predict the correct maximum tube metal temperature (operational constraint) at the end of the runtime.

\subsection{Firebox model}

The zonal method with grey gas assumption (Hottel 1967, Modest 1993) is used to describe the radiative heat transfer in the fire box. The energy balances on $N$ surface zones and $K$ volume zones in terms of surface radiosity $(J)$ and gas emissive power $\left(E_{b g}\right)$ are described as follows (Modest, 1993):

$$
\begin{gathered}
Q_{s i}=A_{i} q_{i}=\sum^{j=N} s_{j} s_{i}\left(J_{i}-J_{j}\right)+\sum^{k=K} g_{k} s_{i}\left(J_{i}-E_{b g k}\right), \quad i=1,2, \ldots N \\
Q_{q i}=4 \kappa V_{i} E_{b q i}-\sum^{j=N} s_{j} g_{i} J_{j}-\sum^{k=K} g_{k} g_{i} E_{b g k}, \quad i=1,2, \ldots K
\end{gathered}
$$

Boundary conditions, heat generation, and convective heat transfer are incorporated in the $Q$ terms on the left side of the equations. The equations are solved with respect to radiosities and gas emissive powers. The present work adopt the following assumptions and approximations:

1. A very important point when describing radiation in this type of furnace, is to represent the burners (gas zones with energy conversion) with correct location, shape, emissive power, and absorption coefficient. This is important because these zones are significantly hotter than the others and the hot spots on the tubes are very often located close to burner clusters.

2. Each burner is modeled with a cone volume shape representing the flame. The nominal cone size is user specified but corrected with the burner heat load.

3. Radiation energy transfer between cold surface zones (reactor tube zones) are neglected. This approximation is acceptable because the emissivity on tube material is high (0.8-0.9) and the radiation from cold tube surfaces is low compared to radiation from burner zones and refractory zones. The temperature difference between reactor tube surfaces in radiation contact is also relatively low.

4. The surface radiosities $(J)$ and the gas emissive powers $\left(E_{b g}\right)$ are solved with a small number of lumped reactor tube primary zones comprising $P$ small secondary zone areas. The number $P$ is usually high and the mean temperatures in a primary zone are calculated from the relationship $A_{i} E_{s i}=\Sigma^{p=P} A_{i p} E_{s i p}$.

With the above approximations one can solve the secondary tube zone emissive power $\left(E_{s i p}\right)$ and thus the distributed tube temperatures as follows:

$Q_{s i p}=A_{i p} q=\varepsilon_{i}\left(A_{i p} E_{b s i p}-\sum^{j=N} s_{j} s_{i p} J_{j}-\sum^{k=K} g_{k} s_{i p} E_{b g k}\right), \quad i=1,2, \ldots R, p=1,2, \ldots P$

$Q_{\text {sip }}$ equals the boundary condition towards the tubular reaction equation (3). Each of the $(R \cdot \mathrm{P})$ equations is solved separately with considerable savings in CPU time. The direct exchange area between two surfaces $\left(s_{j} \mathrm{~s}_{i p}\right)$ and the volume to surface direct exchange area $\left(g_{k} s_{i p}\right)$ are normalized so that $\Sigma^{p=P} g_{k} s_{i p}=g_{k} s_{i}$ and $\Sigma^{p=P} s_{j} s_{i p}=s_{j} s_{i}$. The model used in this optimization study includes 97 gas volume zones, 97 refractory 
Table 1. Simulated and measured (radio trace) relative coking rates (Kopinke et al. 1987, 1993)

\begin{tabular}{lccc}
\hline $\begin{array}{l}\text { Coke } \\
\text { precursor }\end{array}$ & $\begin{array}{c}\text { Kopinke (1987) } \\
\text { Radio trace }\end{array}$ & $\begin{array}{c}\text { Tesner (1984) } \\
\text { model }\end{array}$ & $\begin{array}{c}\text { Edwin (1994) } \\
\text { model }\end{array}$ \\
\hline $\mathrm{C}_{2} \mathrm{H}_{4}$ & 0.73 & 0.73 & 0.73 \\
$\mathrm{C}_{3} \mathrm{H}_{6}$ & $0.83-1.09$ & 0.41 & 1.10 \\
$\mathrm{C}_{4} \mathrm{H}_{6}$ & 1.68 & 1.56 & 1.66 \\
$\mathrm{C}_{2} \mathrm{H}_{2}$ & 5.0 & 11.7 & 5.1 \\
$\mathrm{C}_{3} \mathrm{H}_{4}$ & 2.0 & & 2.0 \\
$\mathrm{CyC}_{5} \mathrm{H}_{6}$ & 2.4 & & 2.4 \\
$\mathrm{C}_{5}+$ & & 0.24 & 1.8 \\
benzene & & 1.63 & \\
toluene & & & \\
\hline
\end{tabular}

wall zones and approximately 2000 reactor tube zones for each coil. Each burner is modeled with individual massbalance and energy balance with convective and radiational energy transfer to other zones. Combustion gas flow pattern description is however only used for the burner zones and the nearest neighbor volume zones. The combustion gas composition $\left(\mathrm{H}_{2} \mathrm{O}, \mathrm{CO}_{2}, \mathrm{CO}, \mathrm{O}_{2}, \mathrm{H}_{2}, \mathrm{~N}_{2}\right)$ is calculated from $\mathrm{C}$, $\mathrm{H}, \mathrm{O}$, and $\mathrm{N}$ balances, and equilibrium assumptions in the following chemical reactions:

$$
\begin{gathered}
\mathrm{CO}+\mathrm{H}_{2} \mathrm{O}=\mathrm{CO}_{2}+\mathrm{H}_{2} \\
2 \mathrm{CO}_{2}=2 \mathrm{CO}+\mathrm{O}_{2}
\end{gathered}
$$

\subsection{Coking models}

The pyrolytic coke formation in the cracking coils is represented with 6 first order reactions and arrenius rate constants proposed by Tesner (1984). Initial coking rate catalized from $\mathrm{Ni}, \mathrm{Fe}$ sites is assumed to be sufficiently suppressed with sulfur feed additives and with inert oxide layers on the inner tube surface. Simulations in Table 1 shows that the relative coking rates predicted by Tesner (1984) are in good agreement with coking rates measured with radio tracer technique (Kopinke et al. 1987, 1993).

The overall coking rate predicted by Tesner (1984) is tuned against coil pressure drop and tube skin temperature measurements. Edwin (1994) presented an additional coking mechanism based on 12 reactions comprising 4 radicals and 6 molecular coke precursors. Tesner (1984) and Edwin (1994) predicts similar coking rates (Table 1) but with some differences in respect to hydrocarbon partial pressure. Both these models shows increased coking rates with increased HC partial pressure, but the model given in Edwin (1994) has however a shift in reaction order, approaching the 1.5 th order for heavy aromatic feed stocks. The differences in apparent reaction order influences mainly the calculated optimal steam dilution level, and thus introduces small uncertainty bands in the calculated absolute optimal trajectories. Experimental studies in the literature supports this uncertainty in apparent reaction order (Lahaye et al., 1977, Dunkleman et al., 1976, Tesner, 1984). However the deviation in reaction order between Tesner (1984) and Edwin (1994) coking models does not influence the calculation of the economical benefit of dynamic optimization compared to steady state optimization in this paper. 
Dynamic Optimization and Production Planning of Thermal Cracking Operation 105

Table 2. Comparison between measured industrial data (Ross and Shu, 1979) and composition simulations

\begin{tabular}{|c|c|c|c|c|c|c|}
\hline Feed & \multicolumn{2}{|c|}{ Ethane (mayor comp.) } & \multicolumn{2}{|c|}{ Propane } & \multicolumn{2}{|c|}{ Butane } \\
\hline $\begin{array}{l}\text { Residences time } \\
\text { Out HC pressure } \\
\text { Out Temp. (Meas/Sim.) }\end{array}$ & \multicolumn{2}{|c|}{$\begin{array}{c}1.39 \mathrm{sec} \\
1.3 \mathrm{ata} \\
829 / 829^{\circ} \mathrm{C}\end{array}$} & \multicolumn{2}{|c|}{$\begin{array}{r}1.35 \mathrm{sec} \\
1.35 \mathrm{ata} \\
834 / 834^{\circ} \mathrm{C}\end{array}$} & \multicolumn{2}{|c|}{$\begin{array}{r}1.07 \mathrm{sec} \\
1.51 \mathrm{ata} \\
793 / 794^{\circ} \mathrm{C}\end{array}$} \\
\hline Effluent. comp. & Meas. & Sim. & Meas. & Sim. & Meas. & Sim. \\
\hline Hydrogen [wt\%] & 3.51 & 3.60 & 1.50 & 1.30 & 0.63 & 0.75 \\
\hline Methane [wt $\%$ ] & 6.43 & 6.26 & 23.35 & 24.35 & 18.94 & 18.79 \\
\hline Acetylene & 0.19 & 0.29 & 0.50 & 0.38 & 0.19 & 0.17 \\
\hline Ethylene & 46.59 & 46.62 & 33.49 & 33.42 & 27.02 & 26.90 \\
\hline Ethane & 37.50 & 37.30 & 4.94 & 5.58 & 6.92 & 7.13 \\
\hline $\mathrm{C}_{3} \mathrm{H}_{4}$ 's & & & 0.20 & 0.25 & 0.30 & 0.26 \\
\hline Propylene & 1.70 & 1.46 & 15.05 & 14.71 & 21.96 & 22.52 \\
\hline Propane & 0.09 & 0.22 & 9.72 & 9.66 & 0.91 & 0.85 \\
\hline Butadiene & 1.25 & 1.34 & 1.92 & 2.20 & 2.19 & 2.42 \\
\hline Butens & 0.31 & 0.21 & 0.90 & 1.06 & 2.54 & 3.04 \\
\hline Butans & 0.29 & 0.33 & 0.11 & 0.04 & 11.18 & 10.72 \\
\hline $\mathrm{C}_{5}+$ & 2.13 & 2.37 & 7.93 & 7.05 & 7.22 & 6.45 \\
\hline
\end{tabular}

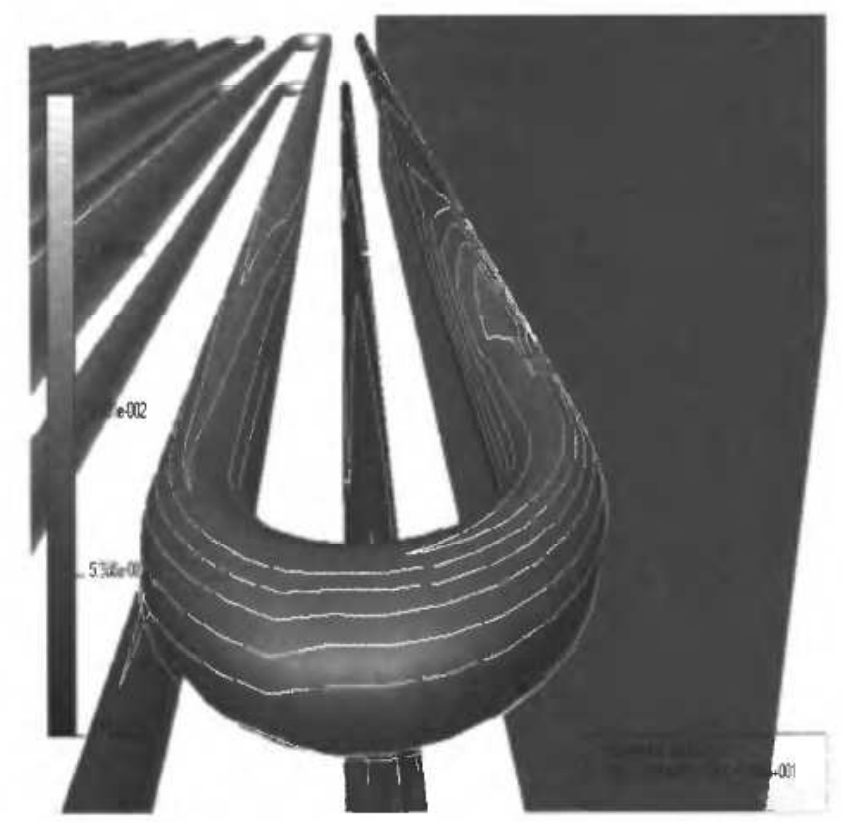

Figure 3. Simulated increased coke layer in an inlet tube because of flame impingement from one burner.

The coking layer in the coils is predicted circumferential, and longitudinal, in the tubes. Figure 3 illustrates how a hot spot caused by flame impingement from one burner, increases the coke layer on an inlet tube.

The TLX coking model is distributed in the longitudinal direction in the TLX tubes. Kinetic parameters and thermal conductivity of the coke are estimated from industrial data on TLX outlet temperatures (Figure 4). 


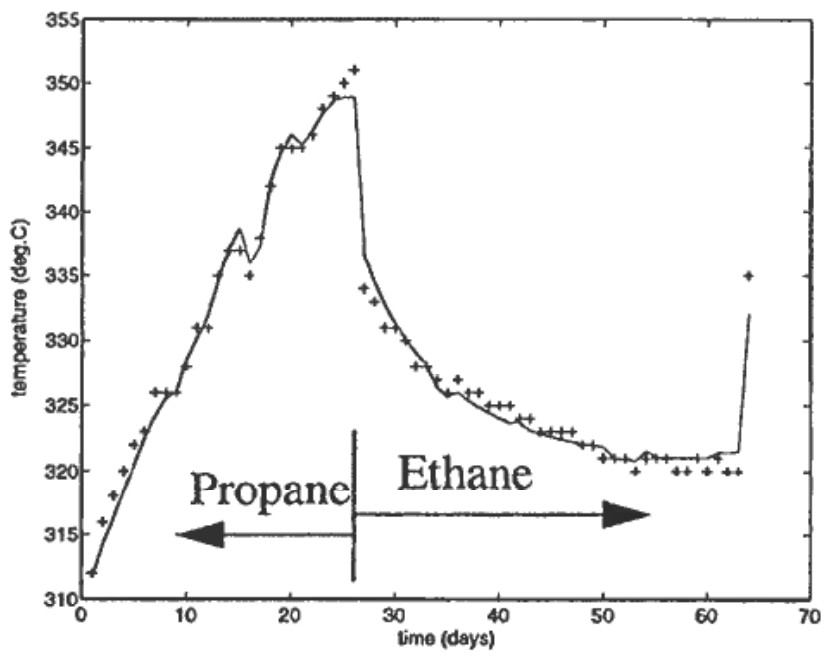

Figure 4. Simulated and measured TLX outlet temperature. Large temperature variations caused by coke and polymer formation in an industrial TLX .

\subsection{Concluding remarks about the models}

All the model components are generic in the sense that the geometrical shape of the units are (to a certain extent) parameterized in configuration files. A lot of effort is put into the modeling and simulation algorithms in order to make this rigorous cracker model computationally fast enough for time scale dynamic optimization tasks. The predictive abilities, combined with short simulation time, makes the model also suitable for other applications (Edwin 1994):

1. On-line identification of cracker effluent composition.

2. Advanced training simulators (dynamics must be added).

3. Modelbased control (dynamics must be added).

4. Mathematical design optimization.

The strong relationship between heaters, steam reformers, and steam cracker design make some basics of this model concept suitable for all 3 types of furnaces. The 3D display of the tube metal temperature in Figure 2 illustrates the details of the model used in this optimization.

Convection section and TLX model are presented in Edwin (1994).

\section{Optimization}

\subsection{The optimization problem}

The proposed time scale optimization scheme finds the optimal time dependent trajectories of the defined free variables over a time interval $\left(t_{p}-t_{0}\right)$. Time dependent piece wise constant trajectories (Figure 5) of reaction severity (conversion), stcamhydrocarbon ratio (St./HC), feed rate, and feedstock (optional) are calculated for a time $\left(t_{p}-t_{0}\right)$ into the future. The production period $\left(t_{p}\right)$ is also a free variable in the optimization, so that the optimal on-stream time is also calculated. The optimization problem is solved with a standard Sequential Quadratic Programming (SQP) package. (Kraft, 1988). The optimiztion problem is formulated as follows: 

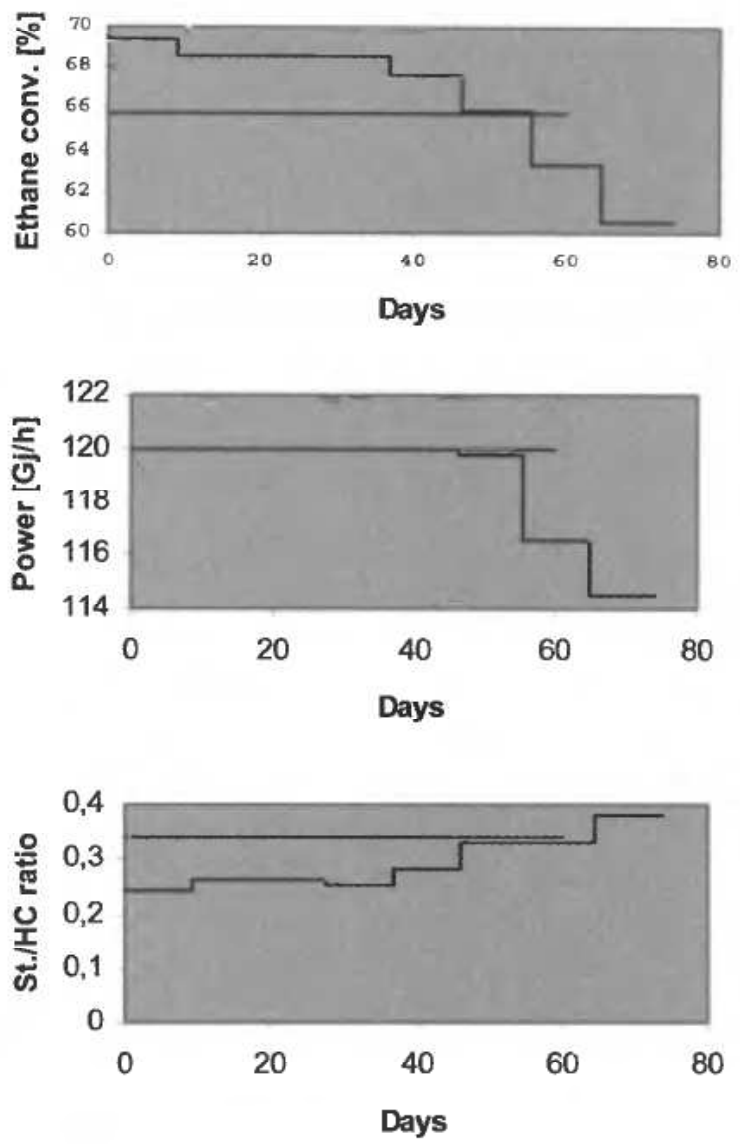

Figure 5. Optimized trajectories (Case 1) of ethane conversion (\%), steam to hydrocarbon ratio (wt. \%/wt.\%) and power consumption $(\mathrm{Gj} / \mathrm{h})$. Steady state optimization indicated with lines.

$$
V=\operatorname{MAX}\left[\frac{t_{p}}{\left(t_{p}-t_{0}\right)\left(t_{p}+t_{d}\right)} \int_{t_{0}}^{t_{p}} \sum F_{i} c_{i}-\sum F_{o} c_{o}-\sum C_{i} \mathrm{~d} t\right], \quad F^{l}<F(u)<F^{u}
$$

where $t_{0}, t_{p}$ and $t_{d}$ are respectively defined as the time from the previous decoking period until present time, total on-stream time period and decoking time period. $\Sigma F_{i} c_{i}$ and $\Sigma F_{o} c_{o}$ are olefin sales rate [\$/h] and paraffin buying rate [\$/h]. $\Sigma C_{i}$ are miscellaneous cost rates; Fuel cost, steam dilution cost, downstream production cost, decoking and maintenance cost, and high pressure steam production (negative cost). The production cost in downstream processing is calculated proportional to plant throughput and the decoking/maintenance cost is calculated as a fixed price for each decoking. $F^{l}<F(u)<F^{u}$ means that the optimization is performed in respect to operational constraints. 3 optimization cases with operational constraint are specified in Table 3. All calculations are done on single cracker operation with initially clean coils and $\operatorname{TLX}\left(t_{0}=0\right)$.

Optimization Case Nos. 1 and 2 specified in Table 3 are furnace constrained, meaning that the cold section of the plant has the capacity to process unlimited feed rate from the crackers in the plant. In these optimizations the lost production in the decoking period has to included in the optimization $\left(t_{d}=4\right.$ days in equation (9)). 
Table 3. Constraints to optimization case Nos. 1-3

\begin{tabular}{lccc}
\hline Constraints & $\begin{array}{c}\text { Optimization Case } \\
\text { No. 1 }\end{array}$ & $\begin{array}{c}\text { Optimization Case } \\
\text { No. 2 }\end{array}$ & $\begin{array}{c}\text { Optimization Case } \\
\text { No. 3 }\end{array}$ \\
\hline Feed stock (main comp.) & Ethane & Propane & Propane/(Ethane) \\
On-stream time $T_{p}$ & $34<T_{p}<93$ & $34<T_{\mathrm{p}}<93$ & $63<T_{\mathrm{p}}<93$ \\
Feed rate $F$ & $12<F<14 \mathrm{~T} / \mathrm{h}$ & $12<F<18 \mathrm{~T} / \mathrm{h}$ & $10<F<16 \mathrm{~T} / \mathrm{h}$ \\
Mean feed rate $G^{u}$ & $G^{u}<14 \mathrm{~T} / \mathrm{h}$ & $G^{u}<16 \mathrm{~T} / \mathrm{h}$ & $G^{u}<13 \mathrm{~T} / \mathrm{h}$ \\
Fuel consumption $P$ & $P<120 \mathrm{Gj} / \mathrm{h}$ & $P<120 \mathrm{Gj} / \mathrm{h}$ & $P<100 \mathrm{Gj} / \mathrm{h}$ \\
TLX outlet temp. $T_{\text {tix }}$ & $T_{\text {tux }}<350^{\circ} \mathrm{C}$ & $T_{\text {tux }}<4000^{\circ} \mathrm{C}$ & $T_{\text {lux }}<350^{\circ} \mathrm{C}$ \\
Tube skin temp. $T_{\text {tube }}$ & $T_{\text {tube }}<1070^{\circ} \mathrm{C}$ & $T_{\text {tube }}<1070^{\circ} \mathrm{C}$ & $T_{\text {tube }}<1054^{\circ} \mathrm{C}$ \\
Coil Inlet temp. $T_{\text {in }}$ & $T_{\text {in }}<690^{\circ} \mathrm{C}$ & $T_{\text {in }}<690^{\circ} \mathrm{C}$ & $T_{\text {in }}<690^{\circ} \mathrm{C}$ \\
$\mathrm{Cr}_{2} \mathrm{O}_{3}$ stability (tube mat.) & Yes & Yes & Yes
\end{tabular}

Optimization Case No. 3 (Table 3) is downstream constrained meaning that one cracker is always in decoking and maintenance mode because of lack of a downstream capacity $\left(t_{d}=0\right.$ in equation (9)).

The cracker design in this work is a conventional type of furnace comprising 4 coils ( 97 meters, $0.8 \mathrm{sec}$. residence time) with one common TLX. Optimization Case No. 3 has a slightly different design than Case Nos. 1 and 2; the max. firing load is app. $20 \%$ lower and the TLX tubes are small bored. This old type of design reach the maximum TLX outlet temperature $\left(350^{\circ} \mathrm{C}\right)$ early in the on-stream period when cracking propane/ butane feed. The problem is related to heavy coking in the small bored TLX tubes and the cracker has to be operated on ethane feed for the last period of the on-stream time (Figure 9).

The optimal dynamic trajectories are compared with steady state constant set points in Figures 5-9 and Table 3. The economics are presented in Table 3. It should be noted that the mean effective conversion is generally higher when dynamically optimized (Figure 8). When the plant is downstream constrained (Case No. 3) the total gas flow $(t / h)$ through the plant is the same in the two optimization methods, but the gas compositions are different. Minor operational constraints in the cold section can then be released or exited. This is not discussed further in this study. It should be noted that the optimum on-stream period is also calculated for the steady state case.

The price on ethylene in the calculations is high ( 450 \$/ton) compared to propylene (100 \$/ton). This favors high conversion and thus activation of more furnace constraints. However earlier calculations with different constraint configurations and

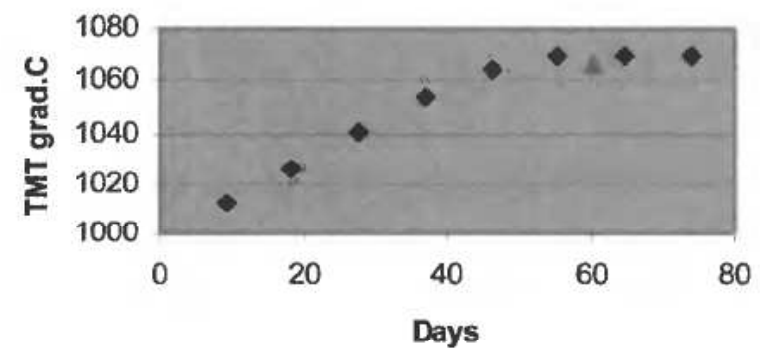

Figure 6. Case 1: Optimized max. tube metal temperatures (Case 1). Steady state end of run temperature indicated with a dot at 60 . 
Dynamic Optimization and Production Planning of Thermal Cracking Operation 109

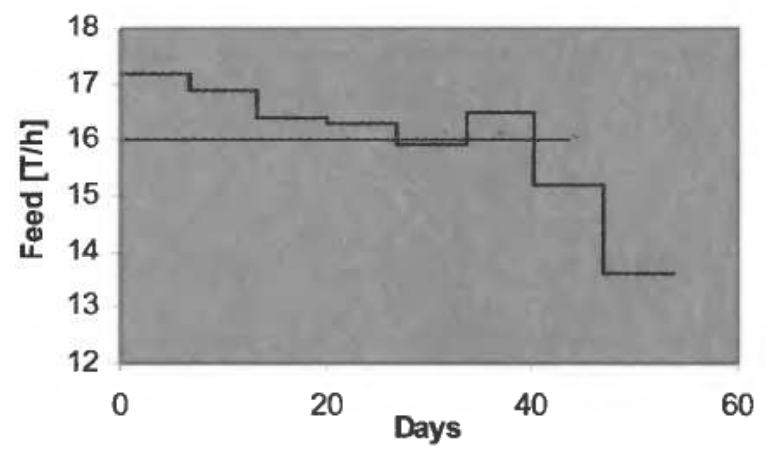

Figure 7. Optimized trajectories (Case 2) of feed rate (ton/h).

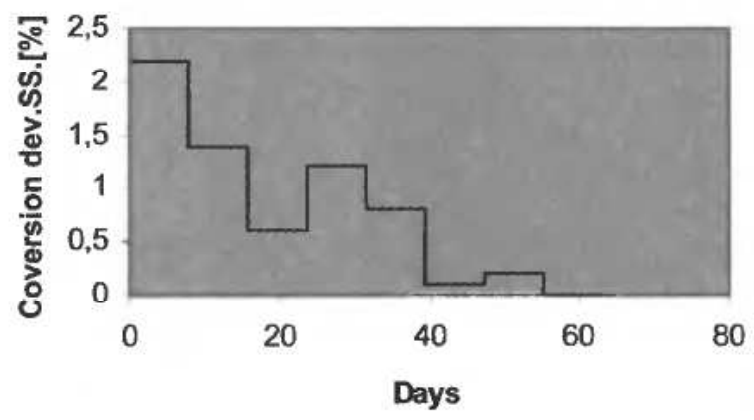

Figure 8. Dynamic optimization increase the effective ethane/propane conversion compared to steady state optimization (Case 3).

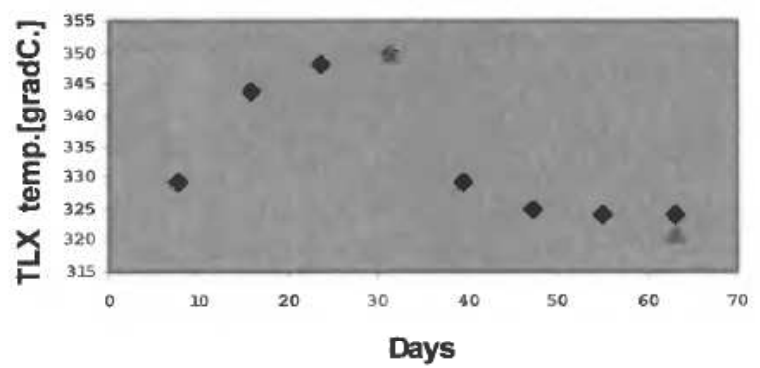

Figure 9. TLX outlet temperature $\left({ }^{\circ} \mathrm{C}\right)$ in dynamic optimization Case 3. Feed change (Propane-ethane) at 32 days on stream. 'Steady state' temperatures indicated with extra dots at 32 days and 63 days on-steam time.

also other prices indicate that there is a significant difference in net earnings (earnings - expenses) between dynamic optimization and steady state optimization. The calculated differences in \% net earning in the present work and in Edwin (1994) indicate a difference of approximately $2 \%$ (Figure 10), which is in the same range reported from steady state optimization implementations alone (Stancato, 1998). 


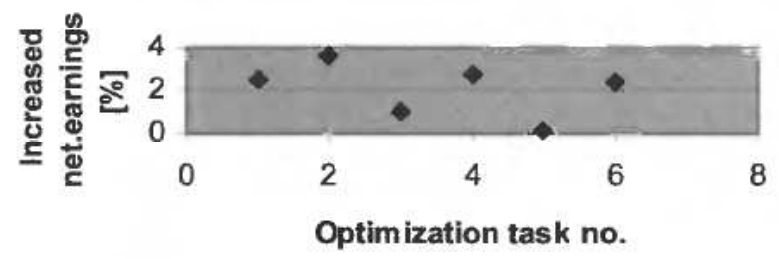

Figure 10. Calculated differences between dynamic optimization and steady state in the present work and Edwin, 1994.

\subsection{Production planning}

The cyclic production - decoking sequences of several crackers in an ethylene plant are difficult to coordinate with operation of the rest of the plant, feed stock availability and customers orders. The above calculations are only concerned with dynamic optimization of one single cracker. The optimization of all crackers in a production schedule is a much larger problem to solve. However, if some manual action and some general rules for operation are utilized, the dynamic optimization scheme for one cracker at a time can provide a very valuable tool for putting up a quasi optimal production plan for several crackers.

The multiple cracker optimization problem is decomposed into $n$ single cracker optimization problems by constraining each furnace total mean feed rate $\left(G_{u}=\right.$ $\left(1 / t_{p} \int^{t_{p}} F \mathrm{~d} t\right)$ during the on-stream period. Thus, it is the total mean production rate during the last $t_{p}$ that is constrained by $G_{u}$ (not the production in the remaining time of a the on-stream period $\left.\left(t_{p}-t_{0}\right)\right)$.

As can be seen in Figures 5 and 7, the severity and the flow rate vary with time. However, the total plant gas composition and throughput variations will level out considerably because multiple crackers in a plant are always at different places in the on-stream period and the peak severity and feed rate are always initially in the production period. However, one of the furnaces must be optimized according to all the plant constraints in order to ensure that the production is pushed to its limits all the time. Optimization of this furnace is solved after the other furnaces and the constraints to every time step is calculated on the basis of all the plant constraints and the optimized operation of the other crackers. This 'control furnace' will tend to vary it's operation parameters more than the other furnaces but it will stabilize the plant trough-put.

The optimal time for decoking $\left(t_{p}\right)$ is sequentially calculated for each cracker and given as advice to the production planner. The production planner puts up the best practical alternative to fit the optimal plan as best as possible. The revised plan usually has some degree of freedom on the new times for decoking $\left(t_{p}\right)$. New optimal $t_{p}$ 's can then be recalculated with the production planners upper and lower constraints given. If there are still degrees of freedom, new $t_{p}$ 's are iteratively calculated according to new constraints.

The constraints $G^{u}$ are generally equal for furnaces with identical feedstock, identical design and operation. However quasi optimal $G^{u}$ could be found for different furnaces (same feedstock) by optimization of equation (9) with respect to $G^{u}$ and $\Sigma G^{u}=$ plant.prod.rate. In practical terms this means that $\mathrm{d} V / \mathrm{d} G^{u}$ for every cracker should be equalized in the final quasi optimal solution.

Feedstock optimization is not discussed here. 
Dynamic Optimization and Production Planning of Thermal Cracking Operation 111

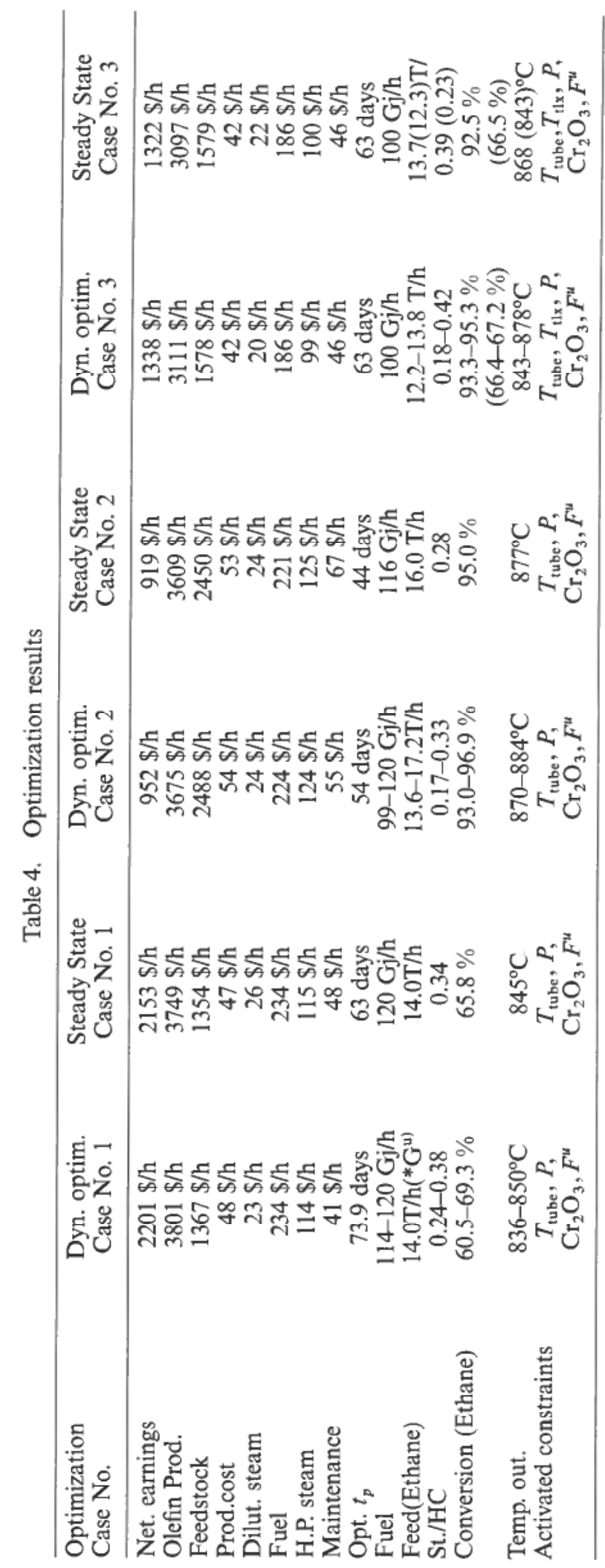




\section{Conclusions}

Calculations indicate that there is a significant difference in net earnings (earnings - expenses) between dynamic optimization and steady state optimization of ethylene furnaces. The calculated differences in $\%$ net earning in the present work and in Edwin (1994) indicate a difference of approximately 2\% (Figure 10). This is in the same range as reported from steady state optimization implementations alone (Stancato, 1998). The calculation is based on rigorous models of the pyrolysis reactions and the coking reactions. Physical models are adopted for the cracker furnace and the TLX. A tool for optimization of production plans based on dynamic optimization is outlined.

\section{Nomenclature}

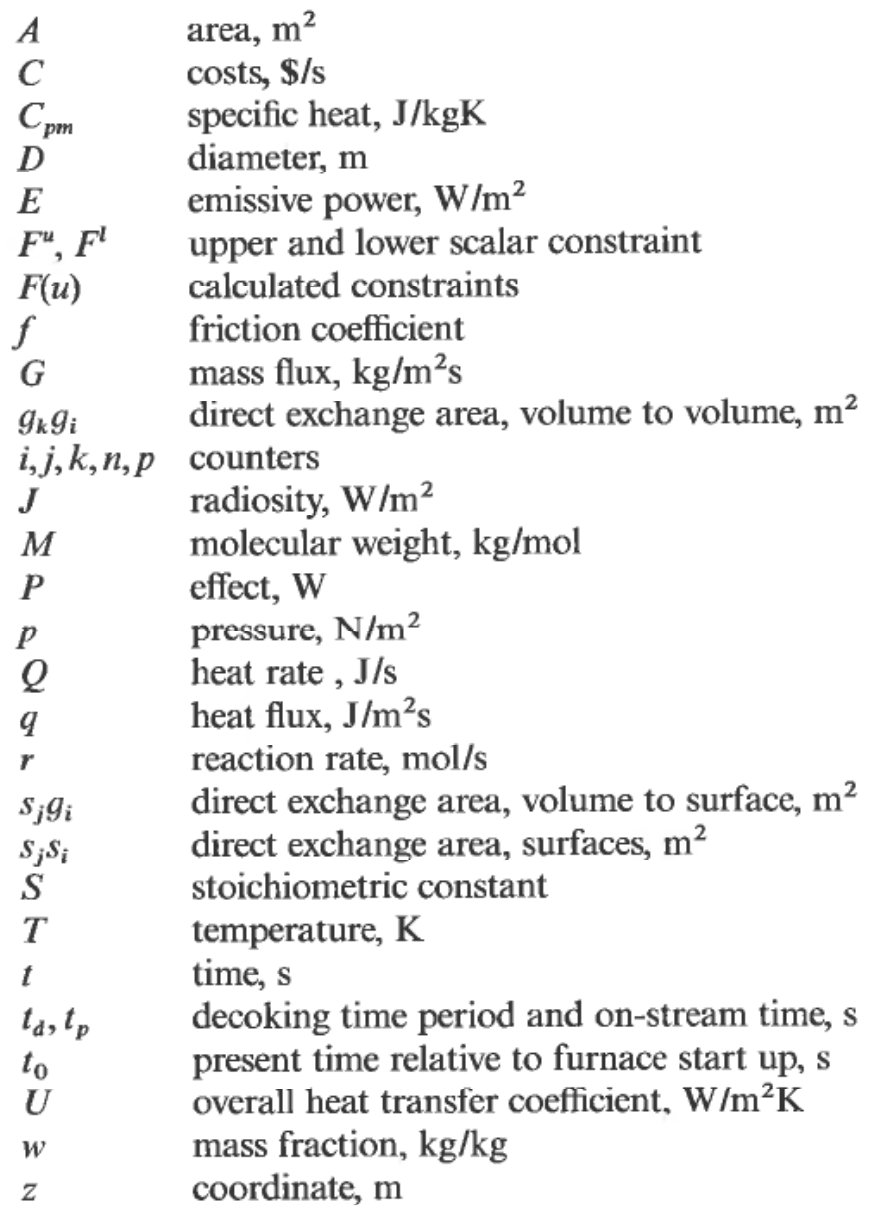

\section{Greek letters}

$\begin{array}{ll}\Sigma F_{o} c_{o} & \text { feed buying rate, } \$ / \mathrm{s} \\ \Sigma F_{i} c_{i} & \text { product sales rate, } \$ / \mathrm{s} \\ \varepsilon & \text { emissivity } \\ \Delta H & \text { heat of reaction } \\ \rho & \text { density } \\ \Phi & \text { coordinate (cylinder) }\end{array}$




\section{References}

Dente, M. E. and RANZI, E. M. (1983). Mathematical modelling of pyrolysis reactions. Industrial and Laboratory Pyrolysis. Chap. 7, Academic Press, New York.

Dente, M. E., Ranzi, E. M., Pierucci, S. J., Bussani, G. M. and Mullick, S. (1990). Evolution of fundamental kinetic model for industrial applications of steam cracking processes., AIChE Annu. Meeting, Chicago (IL), November.

Dunkleman, J. J. and Albright, L. F. (1976). Pyrolysis of propane in tubular flow reactors constructed of different materials. Industrial and laboratory pyrolysis. ACS Symp. Series, Vol. 32, p. 261-273.

EDwin, E. H. (1994). Modeling, Modelbased Control, and Optimization of Thermal Cracking and Ethylene Production. University of Trondhem NTNU, Division of Engineering Cybernetics. Report No. 94-89-W.

Froment, G. F., Van De Steene, B. O. and Van Damme, P. S. (1976). Thermal cracking of ethane and ethane propane mixtures. Ind. Eng. Chem. Proceaa. Dev., Vol. 15, No. 4.

Hottel, H. C. and SARofim, A. F. (1967). Radiative Transfer. McGraw-Hill.

Kopinke, F. D., Zimmerman, G. and NowaK, S. (1988). On the mechanism of coke formation in steam cracking-conclusions from results obtained by tracer experiments. Carbon, Vol. 26, No. 2. p. 117-124.

Kopinke, F. D., Zimmerman, G., Reyniers, G. C. and Froment, G. F. (1993). Relative rates of coke formation from hydrocarbons in steam cracking of naptha. 2. Paraffins, Naphthens, Mono-, Di-, and Cyclo-olefins, and Acetylenes. Ind. Eng. Chem. Res, Vol. 32 , pp. 56-61.

KRAFT, D. (1988). A software package for sequential quadratic programming. DFVLR Institiut fur dynaamik der flugsysteme. Oberpfaffenhofen.

LAHAYE, J., Badie, P. and DuCRET, J. (1977). Mechanisms of carbon formation during steam cracking of hydrocarbons. Carbon, Vol. 15, pp. 87-93.

Modest, F. M. (1993). Radiative Heat Transfer. McGraw-Hill.

Ross, L. L. and ShU, W. R. (1979). Computer Modelling of Hydrocarbon Pyrolysis for Olefin Production. Thermal Hydrocarbon Chemistry Advancees in Chemistry Series, No. 183, Am. Chem. Soc.

Stancato, B. W., Allsford, K. V., Kiayama, Y., Miyoshi, T. and Kuwajima, M. (1998). Analyzing the benefits of online optimization. 1998 Spring National Meeting 10. Ethylene Producers Conference, 9-13 March, New Orleans, Louisiana.

Tesner, P. A. (1984). Kinetics of Pyrolytic carbon formation. Chem. Phys. Carbon, Vol. 19, p. 65 .

Willems, P. A. and Froment, G. F. (1988a). Kinetic modelling of thermal cracking of hydrocarbons. 1. Calculation of frequency factors. Ind. Eng. Chem. Res., 1959-1966.

Willems, P. A. and Froment, G. F. (1988b). Kinetic modelling of thermal cracking of hydrocarbons. 2. Calculation of activation energies. Ind. Eng. Chem. Res., 1971-1977. 